Multidisciplinary Journal - Volume 4, Nomor 1, 2021

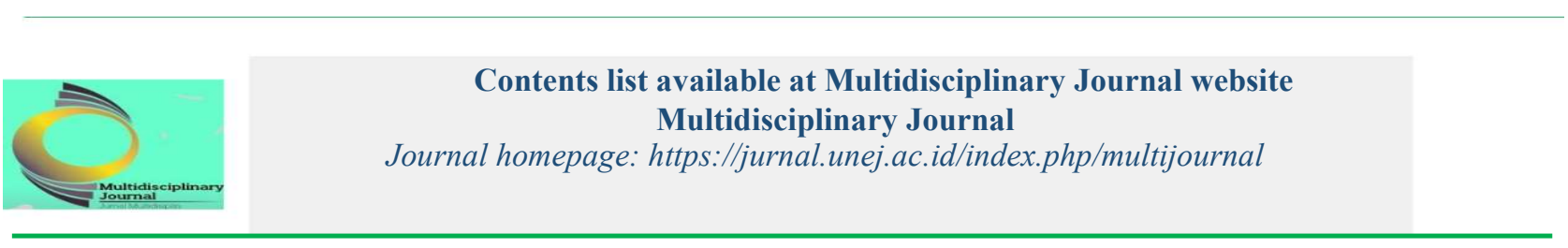

\title{
Studi Sanitasi RSU “ Dr. Koesnadi ” Kabupaten Bondowoso
}

\author{
Study Sanitation at the "Dr. Koesnadi" Hospital Bondowoso \\ Haris Ahmadi,S.KM, ${ }^{1}$ Dr. Isa Ma'rufi. S.KM., M.Kes. ${ }^{2}$
${ }_{\text {Pascasarjana Ilmu Kesehatan Masyarakat Universitas Jember }}^{2}$ Pascasarjana Ilmu Kesehatan Masyarakat Univeristas Jember
ahmadiharis74@gmail.com
}

ABSTRAK : Kualitas lingkungan Rumah Sakit (RS) yang laik sehat baik dari segi fisik, biologi, kimia, dan sosial akan menjadikan sebagai tempat pelayanan kesehatan yang dapat mejamin pemeliharaan dan peningkatan derajat kesehatan masyarakat. RS tempat di mana adanya kontak erat antara manusia (pengunjung, pasien, dan masyarakat) dengan lingkungan sekitarnya, maka RS harus sesuai baku mutu kualitas sanitasi yang sudah diatur dalam perundang-undangan yang berlaku. Laik sehat RS dilakukan untuk mencegah hal - hal yang bisa mengakibatkan masalah menurunnya kualitas sanitasi dan kondisi mutu media sarana sanitasi di rumah sakit, seperti limbah, media air bersih, air minum, pangan, media udara, sarana prasarana dan kualitas bangunan serta vektor/binatang pembawa penyakit sehingga berakibat resiko terjadinya penularan penyakit di dalam rumah sakit itu sendiri. Tujuan Penelitian adalah untuk mengetahui gambaran mutu laik sehat rumah sakit yang ditentukan melalui capaian baku mutu kesehatan lingkungan yang standart dan memenuhi syarat - syarat kesehatan lainnya di RSU "Dr. Koesnadi” Bondowoso. Jenis penelitian ini tergolong deskriptif evaluative yakni ingin memperoleh penjelasan tentang kondisi sanitasi di RS. Subjek penelitian yaitu RSU "dr. Koesnadi" Bondowoso dan lingkungannya menurut acuan penggunaan Formulir Inspeksi Kesehatan Lingkungan (IKL) Rumah Sakit sesuai dengan Permenkes No.007/Menkes/Per/II/2019. Hasil penelitian, secara umum hasil pengawasan dan inspeksi kesehatan lingkungan termasuk kategori sangat baik (total nilai skore 8.840) tetapi masih perlu adanya perbaikan pada variable-variable terutama media kesehatan udara pada aspek standart baku mutu pencahayaan dan kebisingan di ruang ruang tertentu, kesehatan pangan siap saji terutama pada proses mendapatkan sertipikat Laik Sehat Jasa Boga Golongan B dan mengukur angka kepadatan vector yang masih belum dilakukan sehingga akan berpengaruh terhadap kegiatan pengendalian vector.

Kata Kunci: Rumah sakit, kualitas lingkungan, kategori rumah sakit

\begin{abstract}
The quality of the Hospital Environment (RS) that is good in terms of physical, biological, chemical, and social will make it a place of health services that can guarantee the maintenance and improvement of the health status of the community. Hospitals are places where there is close contact between humans (visitors, patients, and the community) with the surrounding environment, then the hospital must comply with the sanitation quality standards that have been regulated in the applicable law. Hospital health worthiness is carried out to prevent things that can cause problems in decreasing the quality of sanitation and the quality condition of hospital sanitation facilities, such as waste, clean water media, drinking water, food, air media, infrastructure and building quality as well as vectors/animals carrying disease. resulting in the transmission of disease in the hospital itself. The purpose of the study was to find out the description of the hospital's health-worthy quality which was determined through the achievement of standard environmental quality standards and fulfilled other health requirements at the "Dr. Koesnadi" Hospital Bondowoso. This type of research is classified as descriptive evaluative, namely wanting to obtain an explanation of the sanitary conditions in the hospital. The research subject is "dr. Koesnadi" Hospital Bondowoso and his environment in accordance with the reference to the use of the Hospital Environmental Health Inspection Form (IKL) in accordance with the Minister of Health Regulation No. 007/Menkes/Per/II/2019. The results of the research, in general the results of environmental supervision and inspection are very good (total score of 8,840 ) but still need improvement on variables, especially air health media on aspects of lighting quality standards and certain spaces, ready food health in the certificate process. Healthy Catering Services Category B and measuring vector density numbers, especially those that are still being carried out so that it will affect vector control activities.
\end{abstract}

Keywords: Hospital, environmental quality, hospital category 


\section{Pendahuluan}

Dalam UU Nomor 36 Tahun 2009 bahwa untuk mengimplementasikan mutu lingkungan yang bersih dan sehat diperlukan upaya kesehatan lingkungan baik fisik, kimia, biologi, dan sosial yang bertujuan untuk meningkatkan derajat kesehatan yang optimal. Pedoman upaya penyelenggaraan kesehatan lingkungan diperkuat dalam Peraturan Pemerintah Nomor 66 Tahun 2014, dalam upaya mencegah kejadian penyakit dan atau gangguan kesehatan lainnya. Upaya sanitasi/kesehatan lingkungan diselenggarakan menuju lingkungan perumahan permukiman, tempat kerja dan rekreasi, serta fasilitas umum lainnya yang sehat, aman, dan terkendali. Adapun tempat dan fasilitas umum yang perlu mendapat pengawasan laik sehat salah satunya adalah rumah sakit.[1]

Pelayanan kesehatan di Rumah Sakit Umum (RSU) diselenggarakan dalam upaya kesehatan perseorangan pada semua bidang dan jenis penyakit dengan menyediakan pelayanan rawat jalan, rawat inap, dan gawat darurat. Berdasar identifikasi dan jumlah tempat tidur untuk rumah sakit umum kelas B minimal harus memiliki 200 (dua ratus) bed untuk memenuhi standart pelayanan yang berkesinambungan.[2]

Rumah sakit sabagai tempat umum mempertemukan manusia dan lingkungan hidup bilamana tidak diselenggarakan dengan baik dan sehat akan mengakibatkan permasalahan kesehatan lingkungan dan turunnya mutu media sanitasi seperti limbah, media air bersih, air minum, pangan, media udara, sarana prasarana dan kualitas bangunan serta vektor/binatang pembawa penyakit sehingga berakibat resiko terjadinya penularan penyakit di dalam rumah sakit itu sendiri. Adapun upaya sanitasi rumah sakit meliputi kesehatan air dan kesehatan udara rumah sakit, kesehatan pangan siap saji, kesehatan sarana prasarana/bangunan, pengendalian vector/binatang penular penyakit, pengamanan limbah, pengamanan radiasi, penyelenggaraan linen, dan manajemen sanitasi RS.

Studi pengamatan/inspeksi kesehatan lingkungan pernah dilakukan di RSUD Prof.Dr.Margono Soekarjo Purwokerto dengan skore/hasil sebesar 93,2\% yang dikategorikan memenuhi syarat, tetapi ada variable yang masih belum memenuhi syarat yakni variable pada pengamanan radiasi. Untuk itu disarankan agar resiko dampak radiasi yang ditimbulkan menjadi perhatian pihak rumah sakit terutama bagian radiologi agar difasilitasi melakukan substitusi dengan cara pemasangan lapisan timah hitam di dinding dan daun pintu pada ruang radiologi.[3]

Tujuan penelitian ini adalah memberikan gambaran sanitasi rumah sakit melalui inspeksi kesehatan lingkungan RS dengan cara penilaian dan pemeriksaan lapangan serta membadingkan antara nilai capaian dengan standart yang baku dan persyaratan kesehatan lingkungan di RSU "dr. Koesnadi” Bondowoso.

\section{Metode Penelitian}

Penelitian ini termasuk penelitian deskriptif evaluatif yakni adanya studi yang menggambarkan secara pesepktif tentang kondisi laik sehat sanitasi RSU "dr. Koesnadi" Bondowoso.

Subjek penelitian yaitu lingkungan RSU "dr. Koesnadi” Bondowoso dan dilakukan inspeksi sanitasi pada tanggal 15 Maret 2021 sesuai acuan Formulir Inspeksi Kesehatan Lingkungan (IKL) Rumah Sakit menurut Permenkes RI
Nomor:007/Menkes/Per/II/2019. Untuk memperoleh data yang diinginkan maka melakukan langkah-langkah melalui observasi, wawancara/tanya jawab dengan pihak rumah sakit dan didokumentasikkan. Format IKL berupa checklist dan kuesioner sesuai dengan lampiran Permenkes RI nomor:007/ Menkes/Per/II/2019.

Data dianalisa dengan analisis deskriptif, yakni melaporkan detail penyelenggaraan kesehatan air dan kesehatan udara rumah sakit, kesehatan pangan siap saji, kesehatan sarana prasarana/bangunan, pengendalian vektor /binatang pengganggu, pengamanan limbah, pengamanan radiasi, penyelenggaraan linen, dan manajemen sanitasi rumah sakit

\section{Hasil Inspeksi Kesehatan Lingkungan}

\section{a. Data Umum}

RSU “dr. Koesnadi” terletak di Jln. Kapten Piere Tendean No.3 Kelurahan Badean Kecamatan Bondowoso Kabupaten Bondowoso dan kelas Rumah Sakit Umum type B_milik pemerintah dengan jumlah tempat tidur 276 unit

\section{b. Kesehatan Air}

Dari hasil pemeriksaan terhadap empat variable pemeriksaan yaitu :[4]

1) Kuantitas air minum : terpenuhi $5 \mathrm{ltr} / \mathrm{TT} / \mathrm{hari}$

2) Kuantitas air keperluan hygiene dan sanitasi : terpenuhi 400-450 ltr/TT/hari

3) Kondisi mutu air minum : sesuai syarat kimia, fisik, mikrobiologi, dan radioaktif

4) Kondisi kualitas air untuk keperluan hygiene dan sanitasi

Dinyatakan memenuhi syarat semua dengan skor maksimal : 1.400

c. Kesehatan Udara

1) Pedoman Baku Mutu Mikrobiologi udara : Pada ruang operasi kondisi kosong dan kondisi ada aktifitas memenuhi syarat pemeriksaan

Nilai Skore $=\mathbf{2 0 0}$

2) Standart baku mutu fisik untuk kelembaban udara: pada semua ruangan memenuhi syarat kelembaban yaitu antara $40-60 \%$, nilai skore $=\mathbf{2 0 0}$

3) Standar baku mutu untuk pencahayaan

Yang memenuhi syarat pada ruang : meja operasi, endoskopi-laboratorium, koridor, tangga dan kantor/administrasi

Dan yang tidak memenuhi syarat di ruang; rawat inap, anastesi pemulihan, operasi umum, rawat jalan, radiologi dan UGD, skore $=\mathbf{8 0}$ (nilai $\mathbf{m a x}$ 200)

4) Standart baku mutu kebisingan

Yang memenuhi syarat pada ruang : pasien/rawat inap, kantor/lobby, ruang cuci, poli gigi, ICU, endoskopi_laboratorium, tangga, Ruang alat/Gudang, dan anastesi pemulihan

Dan yang tidak memenuhi syarat di ruang : operasi umum, ruang umum, koridor, farmasi, ruang isolasi, ambulans, dan radiologi.

Nilai skore $=110$ (nilai $\max 200$ )

5) Kualitas kimia udara ruang

Sudah dilakukan pemeriksaan bulan Pebruari 2021

oleh Persada Laboratorium dengan hasil Memenuhi syarat, Nilai skore $=\mathbf{2 0 0}$

d. Kesehatan Pangan Siap Saji[5] 
1) Tidak memenuhi standart baku mutu pangan siap saji : karena tidak memiliki sertipikat jasa boga golongan $B$, Nilai skore $=0$ (nilai $\max 500$ )

2) Hasil IKL memenuhi syarat jasa boga golongan $B$ Nilai skore $=\mathbf{5 0 0}$

e. Kesehatan Sarana Prasarana/Bangunan

Standar laik sehat dan persyaratan kesehatan untuk sarana prasarana/bangunan rumah sakit diatur dalam Permenkes nomor : 24/Menkes/Per/VI/2016 [6]

1) Toilet pengunjung memenuhi syarat dengan perbandingan 1:20 bagi wanita dan 1:30 bagi pria, skore $=\mathbf{2 0 0}$

2) Toilet Disabilitas tersedia di ruang rawat jalan, penjunjang medis dan IGD, skore $=\mathbf{2 0 0}$

3) Lantai Rumah sakit memenuhi syarat, skore $=\mathbf{2 0 0}$

4) Pintu Rumah Sakit memenuhi syarat, skore $=\mathbf{2 0 0}$

5) Bangunan Atap Rumah Sakit memenuhi syarat, skore $\mathbf{2} \mathbf{2 0 0}$

6) Langit - langit Rumah Sakit memenuhi syarat, skore $=\mathbf{2 0 0}$

f. Pengendalian Vektor/Binatang Pembawa Penyakit

1) Nilai Angka Padatan Vektor memenuhi syarat: MBR Anophles, IH larva Anophles, RR Aedes, ABJ Aedes, MHD Culex, IH culex, MHD Mansonia, IP pinjal tikus, IP lalat dan IP kecoa, Score $=\mathbf{5 0}$ (nilai $\max 500$ )

2) Angka Kepadatan Binatang Pembawa Penyakit memenuhi syarat : Success Trap Tikus $<1$

Nilai Score $=\mathbf{5 0 0}$

g. Pengamanan Limbah

1) Limbah padat domestic memenuhi syarat dengan adanya : penanganan limbah 3R, ada TPS domestic dan diangkut $<2 \times 24$ jam, Nilai Score $=\mathbf{5 0 0}$

2) Limbah padat $B 3$ memenuhi syarat : limbah medis-non medis dipilah dan waktu/lama simpan limbah medis B3 dilakukan dengan benar, ada Tempat Penampungan Sementara B3 yang sudah berijin serta pengolahan limbah B3 milik RS sendiri yang berijin, Nilai score $=\mathbf{5 0 0}$

3) Limbah Cair memenuhi syarat : punya ijin IPAL dan hasil pengolahan limbah cair memenuhi standart, Nilai score $=\mathbf{4 0 0}$

4) Limbah Gas memenuhi syarat :

a) Jadwal sampling pemeriksaan gas buang emisi dan udara luar ambien dikelola dengan benar

b) Mutu gas buang emisi dan partikulat cerobong memenuhi syarat kualitas udara

c) Pelaporan hasil uji limbah gas dilaporkan rutin setahun sekali ke Instansi pemerintah

d) Buangan gas emisi dalam cerobong tinggi dan genset, boiler ada alat penunjang uji emisi

Nilai score $=\mathbf{2 0 0}$

h. Pengamanan Radiasi

Pengamanan radiasi memenuhi syarat :

1) Ada ijin penggunaan alat dari BAPETEN (Badan Pengawas Tenaga Nuklir )

2) Ada alat pelindung radiasi

3) Ada pemantauan pekerja radiasi menggunakan APD

Nilai Score $=\mathbf{1 . 0 0 0}$

\section{i. Penyelenggaraan Linen}

1) Penyelenggaraan linen internal memenuhi syarat:

a) Debit air lancar, cukup dan mutu air memenuhi syarat. Ada kran air panas bertekanan dengan suhu yang sesuai b) Linen infeksius non infeksius terpisah

c) Ruang linen bersih dan linen kotor terpisah

d) Kegiatan tahapan linen berstandart

Nilai score $=\mathbf{7 0 0}$

2) Penyelenggaraan linen eksternal memenuhi syarat ada MoU dan dilakukan pengawasan (ada enam puskesmas yang $\mathrm{MoU}$ dengan rumah sakit untuk penyelenggaraan linen

Nilai Score $=300$

j. Manajemen Sanitasi Rumah Sakit

1) Manajemen Sanitasi RS memenuhi syarat Ada Instalasi sanitasi dan dokumen administrasi sanitasi, dokumen AMDAL, rencana kerja kesling, monev kegiatan kesling, laporan rutin ke direktur dan Dinas Kesehatan

Nilai score $=\mathbf{4 0 0}$

2) Peralatan pemantauan kesling RS lengkap dan sesuai standart minimal

Nilai Score $=\mathbf{3 0 0}$

3) Tenaga kesling di instalasi sanitasi :

S1 Kesling $=3$ orang

D3 Kesling $=7$ orang

Nilai Score $=\mathbf{3 0 0}$

k. Kesimpulan Penilaian

Total Nilai Score $=8.840$ ( Grading IKL RS $=$ Sangat Baik )

\section{Pembahasan}

Dari 10 variabel standart dan persyaratan Kesehatan lingkungan yang dinilai IKL di RS "dr. KOESNADI" menghasilkan nilai score 8.840 (kategori sangat baik) namun beberapa variable harus dilengkapi dan ditingkatkan kualitasnya yaitu :

a. Kesehatan Udara Rumah Sakit

Total score 780 yang seharusnya nilai maksimal adalah 1.000 , adapun yang masih kurang memenuhi syarat adalah

1) Standart Baku Mutu Pencahayaan :

Tabel 1 : Ruangan Tidak Memenuhi Standart Baku Mutu Pencahayaan

\begin{tabular}{|c|l|c|c|}
\hline No & \multicolumn{1}{|c|}{ Ruangan } & $\begin{array}{c}\text { Hasil } \\
(\text { Lux })\end{array}$ & $\begin{array}{c}\text { Standart } \\
(\text { Lux })\end{array}$ \\
\hline 1 & Rawat Inap & 153 & 250 \\
\hline 2 & Rawat Jalan & 64 & 200 \\
\hline 3 & UGD & 135 & 300 \\
\hline 4 & Opr Umum & 150 & 500 \\
\hline 5 & Ans.Pemulihan & 156 & $300-500$ \\
\hline 6 & Radiologi & 44.5 & 60 \\
\hline
\end{tabular}

Direkomendasikan untuk meningkatkan intensitas cahaya pada ruang - ruang yang pencahayaannya kurang memenuhi syarat

2) Kebisingan

Tabel 2 : Ruangan Tidak memenuhi standart baku mutu kebisingan: 
Direkomendasikan untuk menurunkan kebisingan dengan substitusi (mendesain ruangan yang tidak beresiko terjadi gangguan dari suara yang tidak diperkenankan dari luar) atau tanda larangan ramai pada tempat-tempat tertentu yang dekat dengan ruangan tersebut yang masih kurang memenuhi syarat

b. Kesehatan Pangan Siap Saji Rumah Sakit

Total score 500 yang seharusnya nilai maksimal adalah 1.000 , adapun yang masih kurang memenuhi syarat adalah :

- Rumah Sakit Belum mengurusi ijin usaha untuk mendapatkan sertipikat Jasa Boga Golongan B yang seharusnya dikeluarkan oleh Dinas Kesehatan Kabupaten Bondowoso (sesuai dengan Peraturan Menteri Kesehetan RI Nomor:1096 tahun 2011 tentang Hygiene Sanitasi Jasa Boga).

- Walaupun secara internal Inspeksi Kesehatan Lingkungan terhadap instalasi gizi sudah dilakukan dan memenuhi syarat sesuai dengan inspeksi pangan standart Jasa Boga Golongan B[5]

c. Pengendalian Vektor/Binatang Pembawa Penyakit Total Score pada item ini masih 550 (score maksimal $=1.000$ ), adapun yang masih kurang memenuhi syarat dan belum dilakukan oleh instalasi sanitasi RS sesuai dengan Permenkes Nomor:50 tahun 2017 adalah :[7] Angka Kepadatan Vektor yakni :

1) Anophles sp : MBR (Man Biting Rate $)<0.025$ dan I.H (Indeks Habitat) larva $<1$

2) Aedes $s p:$ Resting rate $<0.025$ dan $\mathrm{ABJ} \geq 95 \%$

3) Culex $s p$ : MHD $<1$ dan I.H (Indeks Habitat) larva $<1$

4) Mansonia $s p: \mathrm{MHD}<1$

5) Pinjal : Index Pinjal $<1$

6) Lalat: Index populasi $<2$

7) Kecoa; Index Populasi $<2$

- Yang sudah dilaksanakan untuk angka kepadatan vector hanya angka bebas jentik yaitu 99,77 \%, sedangkan untuk angka kepadatan binatang pembawa penyakit yaitu tikus dengan angka success trap nya 0 ( memenuhi syarat $<1$ )

- Direkomendasikan untuk melakukan survey angka kepadatan vector bersama - sama Dinas Kesehatan Kabupaten Bondowoso (Program P2PTVZ) untuk melakukan spot check survey vector dengan melengkapi peralatan dan bahan survey terlebih dahulu

\section{Kesimpulan :}

Secara umum hasil pemeriksaan dan inspeksi Kesehatan lingkungan di RS "dr. KOESNADI" menunjukkan hasil dengan kategori sangat baik dengan nilai score 8.840 tetapi masih perlu perbaikan pada variable terutama pada

a. Kesehatan Udara Rumah sakit pada aspek standart baku mutu pencahayaan pada ruang - ruang tertentu ( rawat inap, anastesi pemulihan, operasi umum, rawat jalan, radiologi dan UGD ) dan kebisingan pada ruang

\begin{tabular}{|c|l|c|c|}
\hline No & Ruangan & $\begin{array}{c}\text { Hasil } \\
\text { (dBA) }\end{array}$ & $\begin{array}{c}\text { Standart } \\
(\mathbf{d B A})\end{array}$ \\
\hline 1 & Opr Umum & 52.5 & 45 \\
\hline 2 & Ruang Umum & 62 & 45 \\
\hline 3 & Radiologi & 50.5 & 40 \\
\hline 4 & Koridor & 58.2 & 45 \\
\hline 5 & Farmasi & 68 & 65 \\
\hline 6 & Ruang Isolasi & 45.2 & 20 \\
\hline 7 & Ambulans & 67 & 40 \\
\hline
\end{tabular}

( operasi umum, ruang umum, koridor, farmasi, ruang isolasi, ambulans, dan radiologi )

b. Kesehatan pangan siap saji terutama pada proses mendapatkan sertipikat Laik Sehat Jasa Boga Golongan B

c. Angka Kepadatan vector yang masih belum dilakukan sehingga akan berpengaruh terhadap kegiatan pengendalian vector

\section{Saran}

a. Direkomendasikan untuk meningkatkan intensitas cahaya pada ruang - ruang yang pencahayaannya kurang memenuhi syarat

b. Direkomendasikan untuk menurunkan kebisingan dengan substitusi (mendesain ruangan yang tidak beresiko terjadi gangguan dari suara yang tidak diperkenankan dari luar) atau tanda larangan ramai pada tempat-tempat tertentu yang dekat dengan ruangan tersebut yang masih kurang memenuhi syarat

c. Ijin usaha jasaboga golongan B harus segera ditindakalanjuti untuk mendapatkan Sertifikat Laik Sehat Jasaboga dari Kepala Dinas Kesehatan Kabupaten Bondowoso sesuai dengan Permenkes Nomor : 1096 tahun 2011

d. Agar menindaklanjuti kegiatan survey angka kepadatan vector sesuai dengan Peraturan Menteri Kesehtan yang berlaku bersama - sama dengan Dinas Kesehatan Kabupaten Bondowoso (Program P2PTVZ) untuk melakukan spot check survey vector

\section{Referensi}

[1] Menteri Kesehatan Republik Indonesia, "PERATURAN MENTERI KESEHATAN REPUBLIK INDONESIA Nomor 7 TAHUN 2019 TENTANG KESEHATAN LINGKUNGAN RUMAH SAKIT," Peratur. Menteri Kesehat. Republik Indones., 2019.

[2] Menteri Kesehatan RI, "Permenkes No 3 Tahun 2020 Tentang Klasifikasi dan Perizinan Rumah Sakit," Peratur. Menteri Kesehat. Republik Indones., no. 3, pp. 1-80, 2020.

[3] R. S. Prasetyaningsih and Y. Yulianto, "Studi Kondisi Kesehatan Lingkungan Rsud Prof. Dr. Margono Soekarjo Purwokerto Tahun 2016," Bul. Keslingmas, vol. 36, no. 2, pp. 162-169, 2017, doi: 10.31983/keslingmas.v36i2.2983.

[4] Menteri Kesehatan RI, "Peraturan Menteri Kesehatan Republik Indonesia Nomor 492/Menkes/Per/IV/2010 tentang Persyaratan Kualitas Air Minum," Peratur. Menteri Kesehat. Republik Indones., pp. 1-9, 2010.

[5] Menteri Kesehatan Republik Indonesia, "Permenkes RI No 1096/MENKES/PER/VI/2011 Tentang Higiene Sanitasi Jasaboga," Peratur. 
Menteri Kesehat. Republik Indones., 2011.

[6] Menteri Kesehatan RI, "Peraturan Menteri Kesehatan Republik Indonesia Nomor 24/MENKES/PER/VI/2016 tentang Persyaratan Teknis Bangunan dan Prasarana Rumah Sakit," Peratur. Menteri Kesehat. Republik Indones., vol. 152, no. 3, p. 28, 2016.

[7] Menteri Kesehatan RI, "Peraturan Menteri Kesehatan Republik Indonesia Nomor 50 Tahun 2017 Tentang Standar Baku Mutu Kesehatan Lingkungan Dan Persyaratan Kesehatan Untuk Vektor Dan Binatang Pembawa Penyakit Serta Pengendaliannya," Peratur. Menteri Kesehat. Republik Indones., 2017. 